\title{
Metabolic syndrome and 10-year risk of cardiovascular events among schizophrenia inpatients treated with antipsychotics
}

\author{
Shadi Naderyan Fe'lii ${ }^{1}$, Seyed Mojtaba Yassini Ardekani ${ }^{2}$, Hosein Fallahzadeh ${ }^{1}$, Ali Dehghani*1
}

Received: 16 Dec 2017

\author{
Published: 16 Sep 2019
}

\section{Abstract}

Background: The metabolic syndrome is highly prevalent among patients with schizophrenia. This study was conducted to determine the prevalence of metabolic syndrome and the risk of cardiovascular disease in the next 10 years among schizophrenic patients.

Methods: This cross sectional study was performed on 100 Iranian patients with schizophrenia in 2016. The prevalence of metabolic syndrome was determined by adult treatment panel III criteria, and 10-year cardiovascular risk was calculated by Framingham Risk Score. SPSS software was used to perform statistical analysis. Chi-square and Fisher's exact or extended Fisher's exact tests were used to compare dichotomous variables. Also, Mann-Whitney U test was applied to compare the quantitative variables. Significance level was considered to be less than or equal to 0.05 .

Results: In this study, 83 participants $(83 \%)$ were male and $17(17 \%)$ were female. The prevalence of metabolic syndrome was $27 \%$ $(21.7 \%$ in males and $52.9 \%$ in females, $\mathrm{p}=0.015)$. Among all components of metabolic syndrome, low HDL-C in men and abdominal obesity in females were the most common disorders. Based on Framingham Risk Score, 76\%, 16\%, and 8\% of patients had low, intermediate, and high level of risk, respectively. A significant difference was observed between the level of risk among participants with and without metabolic syndrome $(\mathrm{p}=0.042)$.

Conclusion: In this study, patients with schizophrenia showed a high prevalence of metabolic syndrome, but most of them had low risk of developing cardiovascular disease. These results suggest regular screening and early interventions to modify the risk factors of metabolic syndrome.

Keywords: Antipsychotic, Cardiovascular disease, Metabolic syndrome, Schizophrenia

Conflicts of Interest: None declared

Funding: Shahid Sadoughi University of Medical Sciences, Yazd, Iran

\section{*This work has been published under CC BY-NC-SA 1.0 license.}

Copyright $\subseteq$ Iran University of Medical Sciences

Cite this article as: Naderyan Fe'li Sh, Yassini Ardekani SM, Fallahzadeh H, Dehghani A. Metabolic syndrome and 10-year risk of cardiovascular events among schizophrenia inpatients treated with antipsychotics. Med J Islam Repub Iran. 2019 (16 Dec);33:97. https://doi.org/10.47176/mjiri.33.97

\section{Introduction}

Metabolic syndrome (MetS) is a multiplex disorder characterized by several risk factors (1). This disorder can

Corresponding author: Dr Ali Dehghani, adehghani-hmrc@ssu.ac.ir

1. Department of Biostatistics and Epidemiology, Shahid Sadoughi University of Medical Sciences, Yazd, Iran

2. Research Center of Addiction and Behavioral Sciences, Shahid Sadoughi University of Medical Sciences, Yazd, Iran increase the risk of cardiovascular diseases (CVD) $(1,2)$. Thus, diagnosis of MetS seems to be a good idea for iden-

\section{$\uparrow$ What is "already known" in this topic:}

Metabolic syndrome (MetS) is a collection of metabolic disorders associated with increased risk of developing cardiovascular disease (CVD). Patients with schizophrenia, due to medications or unhealthy lifestyle, may be at greater risk of developing MetS. Furthermore, CVD risk in these patients may be higher than the general population.

\section{$\rightarrow$ What this article adds:}

Considering the lack of information about the prevalence of MetS and level of developing CVD risk in patients suffering from schizophrenia in Iran, the authors aimed to conduct this study. Also, here, it was found that the patients had a high prevalence of MetS, but most of them had a low risk of developing CVD. 
tifying the high-risk individuals (3).

The mortality rate of patients with schizophrenia is 2 to 3 times higher than the general population $(4,5)$. Although suicide is an important cause of death among these patients, more cases of mortality are attributed to natural causes of death (5) and cardiovascular diseases are the number one cause (6).

Schizophrenic patients have a higher prevalence of MetS because of several factors such as physical inactivity, unhealthy diet, life stressors, and antipsychotic drugs (7). Many investigators have reported a high prevalence of conventional risk factors for CVD, especially MetS, in patients with schizophrenia (8-10). For example, Grover et al reported that the prevalence of metabolic syndrome among Indian patients was $40 \%$ (11). In Malaysia, Said et al found that the prevalence of MetS in patients with schizophrenia was $46.7 \%$ (10). Other researchers reported $38.1 \%$ prevalence among Egyptian patients (12), 51\% among Australians patients (13), and 67.6\% in British patients (14). In a study by Goff et al, 10-year risk of coronary heart disease (CHD) for male and female schizophrenic patients were significantly higher than the controls (9.4\% vs $7.0 \%$ and $6.3 \%$ vs $4.2 \%$, respectively) (15). In Cardiovascular Lipid and Metabolic Outcomes Research in Schizophrenia (CLAMORS study) by Bobes et al, the overall risk of CHD in 10 years was $6.8 \%$ in patients with schizophrenia. In addition, this risk was significantly greater in males than in females (8.3\% vs $4.5 \%)(16)$.

In Iran, however, only several studies were conducted on the prevalence of MetS and risk of CVD in individuals with schizophrenia (17-20). Considering this lack of information, some comprehensive programs have been established for preventing CVD in these patients.

The present study aimed to determine the prevalence of MetS and to estimate the 10-year risk of CVD in patients with schizophrenia who had been treated with antipsychotic drugs in Yazd province, in the center of Iran.

\section{Methods \\ Study design}

In 2016, this cross sectional study was conducted on 100 schizophrenic patients who were selected using convenience sampling method. Accordingly, patients who had been admitted in the psychiatric hospital and were eligible were studied. The number of samples required for the study was calculated by considering $95 \%$ confidence level, $\mathrm{p}=0.28$ from similar studies, and $\mathrm{d}=0.09$ using the sample size formula for estimating the proportion. Single population proportion formula was then used to determine the sample size. This research was approved by the Ethics Committee of Yazd University of Medical Sciences. One of the participant's parents or next of kin was required to fill out the informed consent.

\section{Participants}

Participants were recruited from the hospitalized patients whose diseases were diagnosed by a psychiatrist clinically according to the fourth edition of Diagnostic and Statistical Manual of Mental Disorders (DSM-IV-TR). All patients were in the acute or chronic phase of the disease and were under the antipsychotic treatment. Exclusion criteria included comorbidity of schizophrenia with other mental illnesses, mental retardation, addiction, familial hyperlipidemia disorder, pregnancy, epilepsy, history of antipsychotics treatment less than one year, and unwillingness to participate in the study.

\section{Demographic and clinical variables}

Patient's age was calculated using the date of birth available from medical records. Other demographic information, including marital status and occupation, were asked from the patients' family members.

Smoking status (yes/no) was also determined by asking the nurse or the patient's family. Drugs used by patients, including antipsychotics, antihypertensive, hypoglycemic, and triglyceride lowering agents were checked using medical records.

Weight was also measured by a calibrated digital scale (Omron, Japan) with light clothes and without shoes (20). In addition, height was measured at standing position and without shoes by a tape fixed on the wall $(13,21)$. Waist circumference was measured by an inelastic tape at standing position while breathing normally at the point midway between the last rib and the top of the iliac crest (22). Furthermore, blood pressure (BP) was measured once using a mercury sphygmomanometer (ALPK2, Japan) in sitting position from the right arm.

All measurements were performed by one person and through the same measuring instruments.

In the next step, 5 milliliter blood specimen was drawn from each individual via venipuncture after 8-12 hours of fasting. Then, the blood samples were kept at room temperature for about 30 minutes. Next, clotted blood samples were centrifuged and the serum was separated. Finally, serum samples were analyzed by an auto analyzer (Alpha Classic, Iran), and Pars Azmoon kit was applied to measure the total cholesterol (TC) triglyceride (TG), high density lipoprotein cholesterol (HDL-C), and fasting blood sugar (FBS). All laboratory tests were performed in a single laboratory.

Moreover, body mass index (BMI) was calculated by the following formula: weight $(\mathrm{Kg}) /$ height $^{2}(\mathrm{~m})$. According to the WHO recommendations for Asian populations, BMI of equal or more than $30 \mathrm{~kg} / \mathrm{m}^{2}$ is considered as general obesity (23). Based on the American Diabetes Association (ADA) guidelines, diabetes was defined as FBS of $126 \mathrm{mg} / \mathrm{dL}$ and higher or consumption of hypoglycemic medications (24). According to the guidelines of National Heart Foundation of Australia, systolic blood pressure of $140 \mathrm{mmHg}$ or above, and/or diastolic blood pressure of 90 $\mathrm{mmHg}$ or more, or consumption of antihypertensive drugs are considered as hypertension (25).

\section{Definition of the MetS}

According to the third report of the National Cholesterol Education Program (also called ATP III), MetS is identified by the presence of 3 or more of the following components: waist circumference (WC) of more than 102 centimeter in males and more than 88 centimeter in females; HDL-C of less than $40 \mathrm{mg} / \mathrm{dL}$ in males and less than 50 
$\mathrm{mg} / \mathrm{dL}$ in females; TG equal to or higher than $150 \mathrm{mg} / \mathrm{dL}$ and/or treatment with triglyceride lowering medications; blood pressure (BP) equal to or higher than 130/85 $\mathrm{mmHg}$ and/or treatment with antihypertensive drugs; fasting glucose of $110 \mathrm{mg} / \mathrm{dL}$ or higher and/or treatment with glucose-lowering agents $(26,27)$.

\section{0-year risk of cardiovascular events}

To estimate the 10-year risk of CVD, Framingham Risk Score (FRS) was used. The FRS is a widely known algorithm for predicting the risk of fatal or nonfatal cardiovascular events, which can be used for identifying people who are at risk. The risk score is calculated separately for males and females using components of age, total cholesterol, smoking status, HDL level, systolic blood pressure, and antihypertensive drugs consumption. Individuals with risk of less than $10 \%$ are considered to be at low risk level, patients with risk of $10 \%-20 \%$ are considered to be at intermediate risk level, and patients who have risk of more than $20 \%$ are considered to be in the high risk group (28).

\section{Statistical analysis}

The analysis was performed using SPSS software. Mean \pm standard deviation and frequency (percentage) were applied for the quantitative and qualitative description of variables, respectively. Chi-square test was then applied to compare dichotomous variables. If frequencies were small in contingency tables, Fisher's exact test or extended Fisher's exact test were used. Mann-Whitney U test was also applied to compare the quantitative variables. In all the statistical tests, differences were considered significant if the $\mathrm{p}$ value was equal to or less than 0.05 .

\section{Results}

Participants included 83 male (83\%) and 17 female (17\%) patients with schizophrenia. The mean age of males was higher than that of females $(44.41 \pm 13.72$ vs $36.76 \pm 12.74$, respectively). The difference in the mean of age between males and females was statistically significant $(\mathrm{p}=0.031)$.

The MetS was met in 27\% (95\%CI: 19-37) of patients. Almost half of the patients (51\%) were active smokers $(60.2 \%$ and $5.9 \%$ of males and females, respectively $\mathrm{p}<0.001)$. The prevalence of MetS in smokers and nonsmokers was not significantly different $(p=0.146)$ (Table 1).

The majority of participants were treated with combination of the first and second generation of antipsychotics.

Table 1. Demographic and clinical characteristics of Metabolic Syndrome versus none Metabolic Syndrome patients

\begin{tabular}{|c|c|c|c|c|c|c|c|}
\hline \multirow[t]{2}{*}{ Items } & \multicolumn{2}{|c|}{ MetS $(n=27)$} & \multicolumn{2}{|c|}{ Non-MetS (n=73) } & \multicolumn{2}{|c|}{ All patients $(n=100)$} & \multirow[b]{2}{*}{$\mathrm{p}$} \\
\hline & $\begin{array}{c}\mathrm{n}(\%) \\
\text { or mean } \pm \text { sd }\end{array}$ & $95 \% \mathrm{CI}$ & $\begin{array}{c}\mathrm{n}(\%) \\
\text { or mean } \pm \mathrm{sd}\end{array}$ & $95 \% \mathrm{CI}$ & $\begin{array}{c}\mathrm{n}(\%) \\
\text { or mean } \pm \mathrm{sd}\end{array}$ & $95 \% \mathrm{CI}$ & \\
\hline Age & $42.74 \pm 12.38$ & $37.84-47.64$ & $43.25 \pm 14.37$ & $39.90-46.60$ & $43.11 \pm 13.80$ & $40.37-45.85$ & $0.957^{\S}$ \\
\hline \multicolumn{8}{|l|}{ Gender } \\
\hline Male & $18(66.7)$ & $46-83$ & $65(89)$ & $80-95$ & $83(83)$ & $74-90$ & \multirow[t]{2}{*}{$0.015^{*}$} \\
\hline Female & $9(33.3)$ & $17-54$ & $8(11)$ & $5-20$ & $17(17)$ & $10-26$ & \\
\hline \multicolumn{8}{|l|}{ Marital status } \\
\hline Single & $17(63)$ & $42-81$ & $44(60.3)$ & $48-71$ & $61(61)$ & $51-71$ & \multirow[t]{3}{*}{$0.678^{\dagger}$} \\
\hline Married & 7 (25.9) & $11-46$ & $24(32.9)$ & $22-45$ & $31(31)$ & $22-41$ & \\
\hline Divorced & $3(11.1)$ & $2-29$ & $5(6.8)$ & $2-15$ & $8(8)$ & $4-15$ & \\
\hline \multicolumn{8}{|l|}{ Job } \\
\hline Employed & $3(11.1)$ & $2-29$ & $9(12.3)$ & $6-22$ & $12(12)$ & $6-20$ & \multirow[t]{2}{*}{$1.00^{*}$} \\
\hline Unemployed & $24(88.9)$ & $71-98$ & $64(87.7)$ & $78-94$ & $88(88)$ & $80-94$ & \\
\hline \multicolumn{8}{|l|}{ Smoking } \\
\hline Yes & $17(63)$ & $42-81$ & $34(46.6)$ & $35-59$ & $51(51)$ & $41-61$ & \multirow[t]{2}{*}{$0.146^{\dagger}$} \\
\hline No & $10(37)$ & $19-58$ & $39(53.4)$ & $41-65$ & 49 (49) & $39-59$ & \\
\hline \multicolumn{8}{|l|}{ Antipsychotic use } \\
\hline FGA & $5(18.5)$ & $6-38$ & $14(19.2)$ & $11-30$ & $19(19)$ & $12-28$ & \multirow[t]{4}{*}{$0.732^{* *}$} \\
\hline SGA & $11(40.7)$ & $22-61$ & $21(28.8)$ & $19-41$ & $32(32)$ & $23-42$ & \\
\hline $\mathrm{FGA}+\mathrm{SGA}$ & $10(37)$ & $19-58$ & $33(45.2)$ & $34-57$ & $43(43)$ & $33-53$ & \\
\hline None & $1(3.7)$ & $0.09-19$ & $5(6.8)$ & $2-15$ & $6(6)$ & $2-13$ & \\
\hline Hypertension & $19(70.4)$ & $50-86$ & $22(30.1)$ & $20-42$ & $41(41)$ & $31-51$ & $<0.001^{\dagger}$ \\
\hline Diabetes mellitus & $5(18.5)$ & $6-38$ & $1(1.4)$ & $0.03-7$ & $6(6)$ & $2-13$ & $0.005^{*}$ \\
\hline General obesity & $9(33.3)$ & $17-54$ & $4(5.5)$ & $2-13$ & $13(13)$ & $7-21$ & $0.001^{* *}$ \\
\hline
\end{tabular}

Table 2. Prevalence of MetS (also, its components) and 10-Year Risk of CVD

\begin{tabular}{|c|c|c|c|c|c|c|c|}
\hline \multirow[t]{2}{*}{ Items } & \multicolumn{2}{|c|}{ Male $(n=83)$} & \multicolumn{2}{|c|}{ Female $(n=17)$} & \multicolumn{2}{|c|}{ All patients $(n=100)$} & \multirow[b]{2}{*}{$\mathrm{p}$} \\
\hline & $\mathrm{n}(\%)$ & $95 \% \mathrm{CI}$ & $\mathrm{n}(\%)$ & $95 \% \mathrm{CI}$ & $\mathrm{n}(\%)$ & $95 \% \mathrm{CI}$ & \\
\hline MetS & $18(21.7)$ & $13-32$ & $9(52.9)$ & $28-77$ & $27(27)$ & $19-37$ & $0.015^{*}$ \\
\hline Abdominal obesity & $21(25.3)$ & $16-36$ & $16(94.1)$ & $71-100$ & $37(37)$ & $28-47$ & $<0.001^{\dagger}$ \\
\hline High TG & $25(30.1)$ & $21-41$ & $8(47.1)$ & $23-72$ & $33(33)$ & $24-43$ & $0.176^{\dagger}$ \\
\hline Low HDL-C & $48(57.8)$ & $46-68$ & $14(82.4)$ & $57-96$ & $62(62)$ & $52-72$ & $0.058^{\dagger}$ \\
\hline High BP & $12(14.5)$ & $8-24$ & $1(5.9)$ & $0.1-29$ & $13(13)$ & $7-21$ & $0.459^{*}$ \\
\hline High FBS & $4(4.8)$ & $1-12$ & $1(5.9)$ & $0.1-29$ & $5(5)$ & $2-11$ & $1.000^{*}$ \\
\hline \multicolumn{8}{|l|}{ 10-Year Risk of CVD } \\
\hline Low Risk & $60(72.3)$ & $61-82$ & $16(94.1)$ & $71-100$ & $76(76)$ & $66-84$ & \\
\hline Intermediate Risk & $15(18.1)$ & $10-28$ & $1(5.9)$ & $0.1-29$ & $16(16)$ & $9-25$ & $0.195^{* *}$ \\
\hline High Risk & $8(9.6)$ & $4-18$ & 0 & $0.1-29$ & $8(8)$ & $4-15$ & \\
\hline
\end{tabular}

CI: Confidence Interval. $\uparrow$ Chi-square test *Fisher's exact test **Extended Fisher's exact test 
Among all the used antipsychotics, MetS group consumed the second-generation antipsychotics (SGA) more frequently, while non-MetS group had more frequent consumption of both the first-generation antipsychotics (FGA) and the SGA (Table 1).

Hypertension and diabetes were significantly more prevalent in MetS group than the non-MetS group $(p<0.001$ and $p=0.005$, respectively) (Table 1$)$.

Prevalence of MetS and 10-year risk of CVD are shown in Table 2. Among all components of MetS, low HDL-C in males and abdominal adiposity in females were the most common disorders (Table 2).

Most of the participants $(76 \%, 95 \% \mathrm{CI}$ : $66-84)$ were at low risk level for developing cardiovascular disease in the next 10 years. In addition, no significant difference was observed between the level of risk among males and females (Table 2). However, levels of risk among people with and without MetS were significantly different $(p=0.042)$; the risk level probability of more than $10 \%$ (intermediate and high risk) in those with MetS was almost 2 times more than that of the non-MetS participants (Table 3).

Among all patients, $21.7 \%$ (95\% CI: $13-32)$ of males and $5.9 \%$ (95\% CI: $0.1-29)$ of females did not have any metabolic abnormality. The majority of males (28.9\%) had 2 components of MetS criteria, whereas most of the female patients $(35.3 \%)$ had 3 (Fig. 1). The mean number of MetS components was significantly higher in males $(1.57 \pm 1.17)$ than in females $(2.53 \pm 1.23)(\mathrm{p}=0.005)$.

\section{Discussion}

The results of this study demonstrated a high prevalence of MetS among patients suffering from schizophrenia. Gender was a factor associated with MetS, and MetS was significantly more prevalent in females than in male patients. Moreover, the calculated 10-year risk for CVD showed that most of the patients were at low risk category.
In this study, prevalence of MetS was $27 \%$, whereas low HDL-C and abdominal obesity were the most prevalent components of MetS in male and female patients, respectively. In India, the prevalence of MetS among patients with schizophrenia was estimated as $29.3 \%$ by Das et al, and the reduced HDL-C was reported as the most common abnormality (29). Tseng et al reported that $41.4 \%$ of their sample, patients with schizophrenia or schizoaffective disorder, had MetS (30). Findings of the present study are consistent with the study of Das et al. This consistency in the results may be due to similar life styles of the studied populations and the type of antipsychotic agents in both studies.

The results of some studies indicated high prevalence of MetS among Iranian patients with schizophrenia (17-20). For example, this prevalence was reported as 30.4\%, 28\%, $27.4 \%$, and $25.7 \%$ by Shakeri et al (20), Nayerifard et al (17), Rezaei et al (19), and Ghoreishi et al (18), respectively.

The results of this study are consistent with the Iranian studies mentioned above, which may be due to similarity in factors related to lifestyle, psychotropic medications, as well as racial and cultural similarities.

In this study, the prevalence of MetS in patients with schizophrenia was higher than that of the general population of Yazd (21.3\%) reported by Rezaianzadeh et al (31). This discrepancy can be related to lack of antipsychotic consumption in the general population, level of physical activity, differences in eating habits, and smoking.

The reasons for the development of MetS in patients with schizophrenia are complex and may be related to genetic factors, side effects of antipsychotic drugs, and unhealthy lifestyle, including smoking, low physical activity, and unbalanced diet. Furthermore, these patients have less access to health care services (32).

In the present study, all patients were hospitalized and received antipsychotic treatment, so the high prevalence

\begin{tabular}{|c|c|c|c|c|c|c|c|}
\hline \multirow{2}{*}{ Categories of Risk } & \multicolumn{2}{|c|}{ MetS $(n=27)$} & \multicolumn{2}{|c|}{ Non- MetS $(n=73)$} & \multicolumn{2}{|c|}{ All patients $(\mathrm{n}=100)$} & \multirow[t]{2}{*}{$\mathrm{p}$} \\
\hline & $\mathrm{n}(\%)$ & $95 \% \mathrm{CI}$ & $\mathrm{n}(\%)$ & $95 \% \mathrm{CI}$ & $\mathrm{n}(\%)$ & $95 \% \mathrm{CI}$ & \\
\hline Low Risk & $16(59.3)$ & $39-78$ & $60(82.2)$ & $71-90$ & $76(76)$ & $66-84$ & \\
\hline Intermediate Risk & $7(25.9)$ & $11-46$ & $9(12.3)$ & $6-22$ & $16(16)$ & $9-25$ & \\
\hline High Risk & $4(14.8)$ & $4-34$ & $4(5.5)$ & $2-13$ & $8(8)$ & $4-15$ & $0.042^{*}$ \\
\hline
\end{tabular}

CI: Confidence Interval. *Extended Fisher's exact test

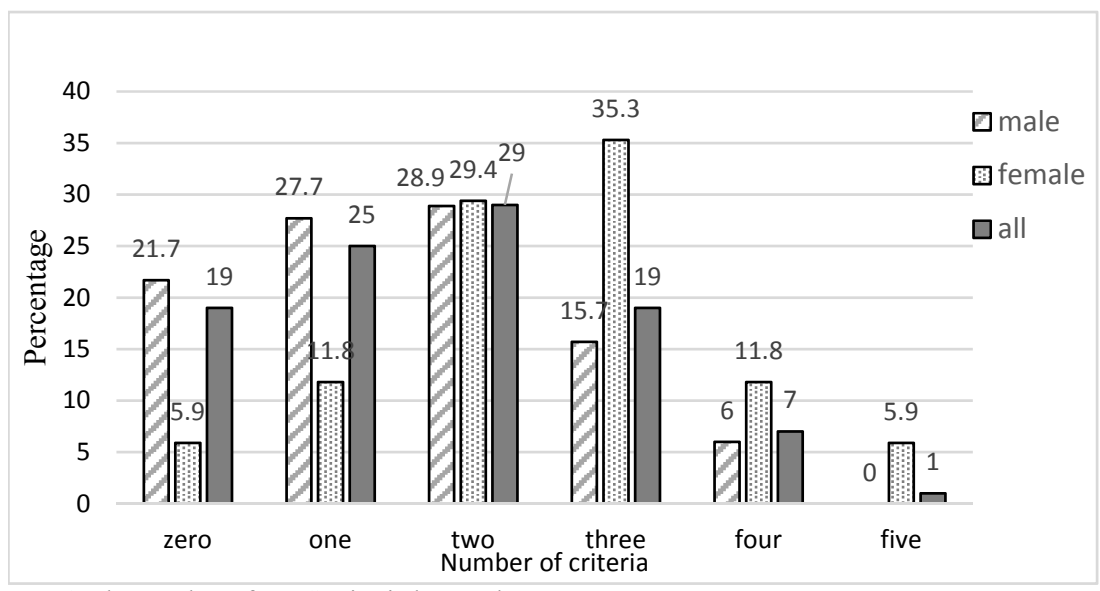

Fig. 1. The number of MetS criteria by gender 
of MetS might have been related to the side effect of antipsychotic agents, physical inactivity, and unbalanced diet, such as low consumption of fruits and vegetables. Moreover, higher prevalence of MetS in female patients than males could be due to high rates of abdominal obesity, high TG level, and low HDL-C level.

No significant difference was found in taking antipsychotics among participants with or without MetS $(p=0.732)$. Tseng et al reported that among patients with schizophrenia or schizoaffective disorder who had MetS, $17.5 \%, 63.5 \%$, and $19 \%$ were taking FGA, SGA, and combination of the first and the second generation antipsychotics, respectively. On the other hand, among patients without MetS, $19.7 \%, 61.2 \%$, and 19.1\% used FGA, SGA, and FGA+SGA, respectively (30). Also, Said et al showed that among patients with schizophrenia who had MetS, $21.4 \%, 50.8 \%$, and $11.9 \%$ received FGA, SGA, and FGA+SGA, respectively (10). The role of antipsychotic agents in increasing the probability of developing metabolic syndrome has been shown in many studies $(29,33$, 34). In fact, cardiometabolic risk factors are higher among treated schizophrenic patients than those who are drug free, especially SGAs are responsible for developing diabetes, weight gain, and dyslipidemia (35).

Patients with schizophrenia have elevated rates of smoking $(5,36)$. These people may consider smoking as a way of self-medication to alleviate negative psychotic symptoms $(37,38)$.

In this study, the prevalence of smoking was $51 \%$, which was higher among patients with MetS than patients without MetS. High prevalence of smoking among these patients was demonstrated by many investigators. For instance, in CLAMORS study, $53.7 \%$ of patients were smokers (16). Said et al also found that prevalence of smoking among patients with schizophrenia was $28.1 \%$ and this prevalence was lower in people with MetS than in those who did not have MetS (10). Marthoenis et al stated that prevalence of smoking in patients with schizophrenia was $68.6 \%$ and MetS was not associated with smoking (39). In Iran, Ghoreishi et al reported that $50.5 \%$ of schizophrenic patients were smokers (18). Prevalence of smoking in this study was in line with the results of CLAMORS study and reports provided by Ghoreishi et al, but the results of the present study were not consistent with the findings of Said study in Malaysia.

With regards to the effect of smoking on raising the risk of MetS (40), the higher prevalence of smoking among participants with MetS, compared to individuals without MetS, is justifiable. The overall prevalence of smoking in our sample was very high which can be due to the following reasons: First, in this study, the frequency of male patients was almost 5 times higher than females and smoking was more common in males than in females. Second, socio-demographic and illness factors, such as age, employment status, level of education, and belief in the tranquility of cigarettes, were affective. Third, at the hospital where this study was conducted, the mental health staff did not encourage patients to stop smoking, as it was difficult for these patients to quit smoking or they had a high tendency to smoke cigarette.
The prevalence of hypertension was $41 \%$ in the present study, which was higher among MetS group than the nonMetS group. The results of a review by Hert et al revealed that the prevalence of hypertension among patients with schizophrenia varied from $19 \%$ to $58 \%$ (6). Ferreira et al indicated that $25 \%$ of patients with schizophrenia had hypertension (41), while Goff et al reported that $17 \%$ of schizophrenic patients were hypertensive (15). The prevalence of hypertension estimated in the present study was similar to the one reported in Hert's review; however, the frequency rate of this study was greater than the one reported by Ferreira et al or Goff et al. The differences between the findings of this study and others may be due to the genetic variations, differences in the life style, and antihypertensive drugs consumption as tranquillizer.

Hypertension in patients with schizophrenia may depend on genetic or environmental factors, such as weight gain, smoking, and sedentary lifestyle. Moreover, antipsychotic agents may lead to obesity that is closely related to the development of hypertension $(42,43)$. However, hypertension may be less frequent in patients with schizophrenia due to the blood pressure lowering effects of some antipsychotic agents (44).

In this study, it was observed that $6 \%$ of participants had diabetes and the prevalence of diabetes in patients with MetS was significantly higher than those without MetS. Goff et al reported that the prevalence of diabetes mellitus was $13 \%$ (15). Furthermore, Said et al stated that the prevalence of diabetes mellitus among patients with schizophrenia was $11.9 \%$ and it was significantly higher in patients with MetS than in those without MetS (10). The estimated prevalence of diabetes mellitus in this study was lower than the rate reported in similar studies, which may be related to different lifestyle factors that vary in different societies. Factors associated with the increased prevalence of diabetes among patients with schizophrenia include family history of diabetes, obesity, physical inactivity, and medication effects $(4,43)$.

In the present study, general obesity was detected in $13 \%$ of the patients. In CLAMORS study, prevalence of obesity was estimated as $30.8 \%$ (16). In Washington, Bell et al stated that $42 \%$ percent of patients with schizophrenia were obese (45). Birkenaes et al also reported that prevalence of obesity among schizophrenic participants was $21.7 \%$ (46). In addition, Grover et al found that the prevalence of obesity among patients with MetS was significantly higher than those without MetS (11).

Prevalence of obesity in the present study was lower than that of similar studies, and the lower prevalence of obesity in the participants of this study, compared to similar studies, may be related to difference in lifestyle factors that vary in different societies.

Among the participants of the current study, $76 \%, 16 \%$, and $8 \%$ had, respectively, low, intermediate, and high levels of risk according to Framingham score. Moreover, the frequency of males with intermediate and high-risk levels of CVD was greater than that of females in these levels. On the other hand, the prevalence of intermediate and high levels of CVD risk among individuals with MetS was significantly higher than those without MetS. Said et 
al reported that $20.8 \%$ of patients with schizophrenia had a high/very high 10-year risk of CHD. In addition, the prevalence of high/very high level of risk was significantly higher among MetS group than non-MetS group (10). Tseng et al further stated that patients with MetS had a significantly higher risk of CVD than patients without MetS, according to FRS. Moreover, they reported that male patients had a significantly higher 10-year risk of CHD than females (30). The findings of this study are consistent with those of Said et al and Tseng et al, which may be due to the similar characteristics of the study populations (such as gender and age). In addition, people with MetS are at 3-fold increased risk of CVD; in fact, the components of MetS that assemble together, increase the risk of developing CVD and each component also increases this risk (47). Thus, in the present study, higher 10-year risk of CVD was expected in patients with MetS than in those without MetS. On the other hand, the higher level of risk among males than females may be due to the higher prevalence of smoking or higher mean of age in males.

This study had important clinical concepts. The patients suffering from schizophrenia had high prevalence of MetS and its components. In addition, the frequency of people at risk of developing CVD, especially among patients who had MetS, was remarkable. Patients with schizophrenia need to regularly check their physical health status, particularly for CVD risk factors. Specific measures are required to modify the risk factors of CVD, such as metabolic risk factors, smoking, lack of physical activity, and unhealthy diet. Furthermore, selecting appropriate antipsychotics and taking into account clinical conditions and side effects are of high importance.

This study had some limitations. First, because of its cross sectional nature, authors were not able to establish casual inferences. Second, due to lack of an appropriate sampling frame, random sampling was not possible and due to the low number of patients, a larger sample could not be gathered. Third, in the current study, outpatients were not included due to low severity of their disease, so the results may not be generalizable to this group. Fourth, it was not clear that whether consumption of antihypertensive drugs (such as Propranolol) by patients was for its sedation effects or for treating the hypertension, thus, the prevalence of hypertension might have been overestimated.

\section{Conclusion}

This study demonstrated that patients with schizophrenia who consumed antipsychotics had an elevated prevalence of MetS. Also, it was found that most of participants were at low risk of developing CVD in the next 10 years, but this risk was high for patients with MetS. Considering the findings of this study as well as other recent reports, psychiatrists and health care staff should be informed about the potential metabolic side-effects of antipsychotics and unhealthy lifestyles among these patients. Furthermore, regular monitoring of metabolic risk factors is suggested. In addition, medical and behavioral interventions should be conducted for patients with MetS.

\section{Acknowledgements}

The authors thank the staff of psychiatric hospital of Yazd for their help with data collection.

\section{Conflict of Interests}

The authors declare that they have no competing interests.

\section{References}

1. Kassi E, Pervanidou P, Kaltsas G, Chrousos G. Metabolic syndrome: definitions and controversies. BMC Med. 2011;9(1):48.

2. Ellingrod VL, Taylor SF, Dalack G, Grove TB, Bly MJ, Brook RD, et al. Risk Factors Associated with Metabolic Syndrome in Bipolar and Schizophrenia Subjects Treated With Antipsychotics: The Role of Folate Pharmacogenetics. J Clin Psychopharmacol. 2012;32(2):261-5.

3. Reilly MP, Rader DJ. The Metabolic Syndrome: More Than the Sum of Its Parts? Circulation. 2003;108(13)1546-1551.

4. De Hert M, Dekker JM, Wood D, Kahl KG, Holt RIG, Möller HJ. Cardiovascular disease and diabetes in people with severe mental illness position statement from the European Psychiatric Association (EPA), supported by the European Association for the Study of Diabetes (EASD) and the European Society of Cardiology (ESC). Eur Psychiatry. 2009;24(6):412-24.

5.Laursen TM, Munk-Olsen T, Vestergaard M. Life expectancy and cardiovascular mortality in persons with schizophrenia. Curr Opin Psychiatry. 2012;25(2):83-8.

6. De Hert M, Correll CU, Bobes J, Cetkovich-Bakmas M, Cohen DAN, Asai I, et al. Physical illness in patients with severe mental disorders. I. Prevalence, impact of medications and disparities in health care World Psychiatr. 2011;10(1):52-77.

7. Asaye S, Bekele S, Tolessa D, Cheneke W. Metabolic syndrome and associated factors among psychiatric patients in Jimma University Specialized Hospital, South West Ethiopia. Diabetes Metab Syndr. in press 2018.

8. Cohn T, Prud'homme D, Streiner D, Kameh H, Remington G. Characterizing coronary heart disease risk in chronic schizophrenia high prevalence of the metabolic syndrome. Can J Psychiatry. 2004;49(11):753.

9. Correll CU, Frederickson AM, Kane JM, Manu P. Equally increased risk for metabolic syndrome in patients with bipolar disorder and schizophrenia treated with second-generation antipsychotics. Bipolar Disord. 2008;10(7):788-97.

10. Said MA, Sulaiman AH, Habil MH, Das S, Bakar AK, Yusoff RM, et al. Metabolic syndrome and cardiovascular risk among patients with schizophrenia receiving antipsychotics in Malaysia. Singapore Med J. 2012;53(12):801-7.

11. Grover S, Aggarwal M, Dutt A, Chakrabarti S, Avasthi A, Kulhara $\mathrm{P}$, et al. Prevalence of metabolic syndrome in patients with schizophrenia in India. Psychiatry Res 2012;200(2):1035-7.

12. Aly El-Gabry DM, Abdel Aziz K, Okasha T, Azzam H, Okasha A. Antipsychotic Polypharmacy and Its Relation to Metabolic Syndrome in Patients With Schizophrenia: An Egyptian Study. J Clin Psychopharmacol. 2018;38(1):27-33

13. John AP, Koloth R, Dragovic M, Lim S. Prevalence of metabolic syndrome among Australians with severe mental illness. Med J Aust 2009;190(4):176-179.

14. Heald A, Pendlebury J, Anderson S, Narayan V, Guy M, Gibson M, et al. Lifestyle factors and the metabolic syndrome in Schizophrenia: a cross-sectional study. Ann Gen Psychiatry. 2017;16(1):12.

15. Goff DC, Sullivan LM, McEvoy JP, Meyer JM, Nasrallah HA, Daumit GL, et al. A comparison of ten-year cardiac risk estimates in schizophrenia patients from the CATIE study and matched controls. Schizophr Res. 2005;80(1):45-53.

16. Bobes J, Arango C, Aranda P, Carmena R, Garcia-Garcia M, Rejas J. Cardiovascular and metabolic risk in outpatients with schizophrenia treated with antipsychotics: results of the CLAMORS Study. Schizophr Res. 2007;90(1):162-73.

17. Nayerifard R, Bureng MA, Zahiroddin A, Namjoo M, Rajezi S. Comparison of metabolic syndrome prevalence in patients with schizophrenia and bipolar I disorder. Diabetes Metab Syndr. 2017;11 Suppl 1:S411-S416.

18. Ghoreishi A, Shajari Z, Sharifi F, Ghoreishi A. Metabolic Syndrome, 10year - Coronary Heart Disease and 8 year-Diabetes 
Mellitus Prediction in the Patients with Schizophrenia. Adv Bio Res. 2016;7(4):155-62.

19. Rezaei O, Khodaie-Ardakani MR, Mandegar MH, Dogmehchi E, Goodarzynejad H. Prevalence of metabolic syndrome among an Iranian cohort of inpatients with schizophrenia. Int J Psychiatry Med. 2009;39(4):451-62.

20. Shakeri J, Karimi K, Farnia V, Golshani S, Alikhani M. Prevalence of Metabolic Syndrome in Patients with Schizophrenia Referred to Farabi Hospital, Kermanshah, Iran. Oman Med J 2016;31(4):270-5.

21. Ferreira L, Belo A, Abreu-Lima C. A case-control study of cardiovascular risk factors and cardiovascular risk among patients with schizophrenia in a country in the low cardiovascular risk region of Europe. Rev Port Cardiol. 2010;29(10):1481-93.

22. WHO Expert Consultation. Waist circumference and waist-hip ratio. Geneva: World Health Organization; [updated 2008 Dec 8; cited 2017 Dec 16] Available from: http://www.WHO.int

23. WHO Expert Consultation. Appropriate body-mass index for Asian populations and its implications for policy and intervention strategies. Lancet. 2004;363(9403):157.

24. American diabetes association. Standards of medical care in diabetes. Diabetes Care. 2017;40 Suppl 1:s13.

25. Gabb GM, Mangoni AA, Anderson CS, Cowley D, Dowden JS, Golledge $J$, et al. Guideline for the diagnosis and management of hypertension in adults. Med J Aust. 2016;205(2):85-9.

26. Santini I, Stratta P, D'Onofrio S, De Lauretis I, Santarelli V, Pacitti $\mathrm{F}$, et al. The metabolic syndrome in an Italian psychiatric sample: a retrospective chart review of inpatients treated with antipsychotics. Riv Psichiatry. 2016;51(1):37-42.

27. Scott MG, Dian B, Luther TC. Third report of the National Cholesterol Education Program (NCEP) expert panel on detection, evaluation, and treatment of high blood cholesterol in adults (Adult Treatment Panel III) final report. Circulation. 2002;106(25).

28. National Heart Lung and Blood Institute. Estimate of 10-year risk for coronary heart disease Framingham point scores. Washington DC: National Heart Lung and Blood Institute; [updated 2014 Sep 14; cited 2017 Dec 16]. Available from: www.nhlbi.nih.gov.

29. Das D, Bora K, Baruah B, Konwar G. Prevalence and predictors of metabolic syndrome in schizophrenia patients from Assam. Indian J Psychiatry. 2017;59(2):228-32.

30. Tseng PT, Wang HY, Cheng YS, Shen FC, Lin PY, Wu CK. The metabolic syndrome and risk of coronary artery disease in patients with chronic schizophrenia or schizoaffective disorder in a chronic mental institute. Kaohsiung J Med Sci 2014,30(11)579-586.

31. Rezaianzadeh A, Namayandeh SM, Sadr SM. National Cholesterol Education Program Adult Treatment Panel III Versus International Diabetic Federation Definition of Metabolic Syndrome, Which One is Associated with Diabetes Mellitus and Coronary Artery Disease? Int J Prev Med. 2012;3(8):552-8.

32. Vancampfort D, Probst M, Scheewe T, De Herdt A, Sweers K, Knapen J, et al. Relationships between physical fitness, physical activity, smoking and metabolic and mental health parameters in people with schizophrenia. Psychiatry Res. 2013;207(1-2):25-32.

33. Mitchell AJ, Vancampfort D, Sweers K, van Winkel R, Yu W, De Hert M. Prevalence of metabolic syndrome and metabolic abnormalities in schizophrenia and related disorders - a systematic review and meta-analysis. Schizophr Bull. 2013;39(2):306-18.

34. Vancampfort D, Stubbs B, Mitchell AJ, De Hert M, Wampers M, Ward PB, et al. Risk of metabolic syndrome and its components in people with schizophrenia and related psychotic disorders, bipolar disorder and major depressive disorder: a systematic review and metaanalysis. World Psychiatr. 2015;14(3):339-47.

35. Ventriglio A, Gentile A, Stella E, Bellomo A. Metabolic issues in patients affected by schizophrenia: clinical characteristics and medical management. Front Neurosci. 2015;9:297.

36. Dickerson F, Schroeder J, Katsafanas E, Khushalani S, Origoni AE, Savage C, et al. Cigarette Smoking by Patients With Serious Mental Illness, 1999-2016: An Increasing Disparity. Psychiatr Serv. 2017,68(9):1-7.

37. Baker AL, Lubman DI, Hides L. Smoking and schizophrenia: treatment approaches within primary care. Prim Psychiatry. 2010;17(1):49.

38. Campion J, Checinski K, Nurse J, McNeill A. Smoking by people with mental illness and benefits of smoke-free mental health services. Adv Psychiatry Treat. 2008;14(3):217-28

39. Marthoenis M, Aichberger MC, Puteh I, Syahrial S, Schouler-Ocak
M. Metabolic syndrome among psychiatric inpatients with schizophrenia in Indonesia. Asian J Psychiatry. 2015;15(Supplement C):10-4.

40. Hert M, Schreurs V, Vancampfort D, Winkel R. Metabolic syndrome in people with schizophrenia: a review. World Psychiatry. 2009;8(1):15-22.

41. Ferreira L, Belo A, Abreu-Lima C. A case-control study of cardiovascular risk factors and cardiovascular risk among patients with schizophrenia in a country in the low cardiovascular risk region of Europe. Rev Port Cardiol. 2010;29(10):1481-93.

42. Johannessen L, Strudsholm U, Foldager L, Munk-Jørgensen P. Increased risk of hypertension in patients with bipolar disorder and patients with anxiety compared to background population and patients with schizophrenia. J Affect Disord. 2006;95(1):13-7.

43. Liao CH, Chang CS, Wei WC, Chang SN, Liao CC, Lane HY, et al. Schizophrenia patients at higher risk of diabetes, hypertension and hyperlipidemia: A population-based study. Schizophr Res. 2011;126(1):110-6.

44. Leucht S, Burkard T, Henderson J, Maj M, Sartorius N. Physical illness and schizophrenia: a review of the literature. Acta Psychiatry Scand. 2007;116(5):317-33.

45. Bell RC, Farmer S, Ries R, Srebnik D. Metabolic risk factors among medicaid outpatients with schizophrenia receiving second-generation antipsychotics. Psychiatry Serv. 2009;60(12):1686-1689.

46. Birkenaes AB, Opjordsmoen S, Brunborg C, Engh JA, Jonsdottir H, Ringen PA, et al. The level of cardiovascular risk factors in bipolar disorder equals that of schizophrenia: a comparative study. J Clin Psychiatry. 2007;68(6):917-23.

47. O'Neill S, O'Driscoll L. Metabolic syndrome: a closer look at the growing epidemic and its associated pathologies. Obes Rev. 2015;16(1):1-12 